\title{
Preparation and Characterization of Nanofibrous Polymer Scaffolds for Cartilage Tissue Engineering
}

\author{
Jarosław Markowski, ${ }^{1}$ Anna Magiera, ${ }^{2}$ Marta Lesiak, ${ }^{3}$ \\ Aleksander L. Sieron, ${ }^{3}$ Jan Pilch, ${ }^{1}$ and Stanislaw Blazewicz ${ }^{2}$ \\ ${ }^{1}$ Laryngology Department, Medical University of Silesia, 20 Francuska Street, 40-752 Katowice, Poland \\ ${ }^{2}$ Faculty of Materials Science and Ceramics, AGH University of Science and Technology, 30 Mickiewicza Avenue, \\ 30-059 Krakow, Poland \\ ${ }^{3}$ Department of General, Molecular Biology and Genetics, Medical University of Silesia, 18 Medykow Street, 40-752 Katowice, Poland
}

Correspondence should be addressed to Stanislaw Blazewicz; blazew@agh.edu.pl

Received 22 October 2014; Revised 19 December 2014; Accepted 19 December 2014

Academic Editor: Miguel A. Correa-Duarte

Copyright (C) 2015 Jarosław Markowski et al. This is an open access article distributed under the Creative Commons Attribution License, which permits unrestricted use, distribution, and reproduction in any medium, provided the original work is properly cited.

Polymer substrates obtained from poly(lactic acid) (PLA) nanofibres modified with carbon nanotubes (CNTs) and gelatin (GEL) for cartilage tissue engineering are studied. The work presents the results of physical, mechanical, and biological assessment. The hybrid structure of PLA and gelatine nanofibres, carbon nanotubes- (CNTs-) modified PLA nanofibres, and pure PLA-based nanofibres was manufactured in the form of fibrous membranes. The fibrous samples with different microstructures were obtained by electrospinning method. Microstructure, physical and mechanical properties of samples made from pure PLA nanofibres, CNTs-, and gelatin-modified PLA-nanofibres were studied. The scaffolds were also tested in vitro in cell culture of human chondrocytes collected from patients. To assess the influence of the nanofibrous scaffolds upon chondrocytes, tests for cytotoxicity and genotoxicity were performed. The work reveals that the nanofibrous structures studied were neither genotoxic nor cytotoxic, and their microstructure, physical and mechanical properties create promising scaffolds for potential use in cartilage repairing.

\section{Introduction}

Trauma or injuries related to cartilage tissues usually lead to progressive tissue degeneration and eventual depletion of healthy cartilage, which can induce pain and discomfort. Clinical treatments to repair diseased or injured cartilage are limited to regenerate functional cartilage in terms of both its composition and mechanical properties $[1,2]$. In case of laryngology, the problem relates to the upper respiratory tract atresia (neoplasms, injuries). Reconstruction of upper respiratory tract in case of neoplasms, traumas of mechanical, thermal, or chemical origin, and postintubation and posttrauma stenoses is a medical problem, which still remains without a solution. The materials used so far, autogenous as well as plastic ones, fail to give results that would be satisfying for patients and surgeons [3-5]. This is the reason for searching for effective methods with the use of various biomaterials. Developing a biologically active material for repairing the defects in upper respiratory tract and reconstructing the defective structures which occurred in patients due to neoplasms as well as in treatment of stenoses or traumas of mechanical, thermal and postintubation origin is the challenge of regenerative medicine and material engineering. The investigation has focused on the use of tissue engineering approaches to repair cartilage tissue with the use of nonfibrous hydrogels as cell carriers injected into defect sites, and mesenchymal stem cells are often cell source for cartilage tissue and hydrogel as a support for MSC chondrogenesis $[6,7]$. A particular role in tissue engineering may play polymer tissue scaffolding, based on nanofibers. Fibrous scaffolds in cartilage tissue engineering are more and more interesting due to their potential to mimic the nanofibrous nature of the extracellular matrix and ability to direct matrix organization [8]. PCL nanofibers used for cartilage scaffold have been shown to support cell infiltration and also MSC chondrogenesis $[9,10]$. Various polymer fibrous structures 
in nanoscale obtained by electrospinning were studied. The method has gained interest due to its ability to form a space fibrous architecture similar to the natural extracellular matrix [11-13]. Moreover, due to a wide range of technical facilities of electrospun fibers the method allows creating directionally dependent space architecture of nanofibers (anisotropic cell supports) which mimic natural tissues [14, 15]. Articular cartilage consists, besides others, of aligned collagen fiber network, which is assumed to be a critical factor required for restoration of its biomechanical functions [16]. While several studies were made in developing porous, isotropic polymerbased scaffolds for tissue engineering and in the manufacture of bulk scaffolds modified with different nanoconstituents, nanofiber-based scaffolds have not yet been extensively studied. Considering the similarities between the electrospun nanofibers and the extracellular matrix, structures fabricated by ES technique create promising materials for scaffolds to regenerate cartilage [17-19] and neural tissue [20-25].

The purpose of our work was to manufacture polymer nanofibrous substrates differing in bioresorbable polymer composition and microstructure designed for cartilage scaffolds. The electrospun polymer scaffolds were modified to obtain three different microstructures. The hybrid structure of PLA and gelatine nanofibres, carbon nanotubes- (CNTs-) modified PLA nanofibers, and pure PLA-based nanofibres was manufactured in the form of thin membranes.

The hybrid PLA/gelatine structure enables the introduction of different components into the solutions used. Gelatine is known to be a moderator of resorption time of PLA [26]. The choice of CNTs was associated with their already confirmed ability to promote cells formation and cells viability [27-30]. It was also proved that carbon nanotubes modify electrical and mechanical properties of PLA fibres, the parameters which are important while designing scaffold for cartilage tissue regeneration [31-33]. Considering carbon nanotubes in medical applications their biocompatibility is the subject of numerous works. Many authors have tackled this problem suggesting some negative influence on cells and human body $[29,34,35]$; however opinions about the biocompatibility of CNTs in vitro and in vivo environment are not consistent. What should be noted as well is the fact that some researchers claim that functionalised CNTs are less toxic and only slightly affect cells' viability $[36,37]$.

The scaffolds were studied in vitro, in cell culture of human chondrocytes collected from patients. In order to assess the influence of the nanofibrous scaffolds upon chondrocytes, tests for cytotoxicity and genotoxicity were performed.

\section{Materials and Methods}

2.1. Preparation of the Scaffolds. Nanometric fibrous polymer scaffolds were prepared by electrospinning technique. The PLA polymer (Ingeo Biopolymer 3251D) and gelatine (GEL) (POCH, analytical grade) were used to manufacture the polymer nanofibres. As solvents dichloromethane (DCM) (POCH, analytical grade), N,N-dimethylformamide (DMF) (POCH, analytical grade), and concentrated (99.5-99.9\%) acetic acid $\left(\mathrm{CH}_{3} \mathrm{COOH}\right)(\mathrm{POCH}$, analytical grade) were used. The PLA solution in the concentration of $15 \%(\mathrm{wt} / \mathrm{v})$ was prepared in mixed solvents DCM and DMF $3: 1$ (wt : wt). The GEL solution in the concentration of $20 \%$ (wt/v) was prepared in concentrated acetic acid. One type of nanofibres was electrospun from polymer solution additionally containing functionalized multiwall carbon nanotubes (CNTs). CNTs were provided by NanoAmor, USA. The nanotubes synthesized by CVD method with the use of nickel as catalyst had diameters in the range of $10-30 \mathrm{~nm}$ and were $1-2 \mu \mathrm{m}$ long. To remove the metallic residues the nanotubes $(1.2 \mathrm{wt} \% \mathrm{Ni})$ were chemically oxidized in a mixture of concentrated $\mathrm{H}_{2} \mathrm{SO}_{4}$ and $\mathrm{HNO}_{3}$ acids, according to the procedures described in detail elsewhere [32]. The concentration of nickel in CNTs after purification was $0.1 \mathrm{wt} \%$.

The suspension of CNTs in DMF $(0.03 \mathrm{~g} / \mathrm{mL})$ was mixed with polymer solution. Before being used, all the polymer solutions were homogenised with magnetic stirrer under gentle heating during 24 hours. PLA solutions with the addition of CNTs were also homogenised using ultrasonic cleaner for 1 hour. The laboratory electrospinning equipment was designed and constructed at the Department of Biomaterials, AGH-UST. To electrospin a $10 \mathrm{~mL}$ syringe, ended with a needle, was loaded with the polymer solution. The voltage of $12 \mathrm{kV}$ was applied between the needle tip and the grounded rotating aluminium mandrel covered with aluminium foil. The tip-to-collector distance was $3 \mathrm{~cm}$. The collector was rotating at the speed of $100 \mathrm{rev} / \mathrm{min}$ during collection to align the nanofibres on aluminum foil. Processing variables were optimized to assure the minimum bead-free polymer fiber substrate. The details of these experiments have already been published elsewhere [38].

The following types of samples were prepared:

PLA-spun from 15\% PLA (wt/v) in DCM and DMF
(3:1wt:wt);
PLA + CNT-spun from 15\% PLA (wt/v) in DCM and
DMF $3: 1$ (wt: wt), containing 1\% (wt) CNTs;

PLA + GEL (hybride scaffold) spun from 15\% PLA (wt/v) in DCM and DMF (3:1 (wt:wt))/20\% GEL (wt/v) in $\mathrm{CH}_{3} \mathrm{COOH}$.

2.2. Scaffolds Characteristics. The samples obtained were coated with gold and analysed using scanning electron microscope, SEM (JROL 5400 microscope with EDS analyser). Single fibre diameters and porosity of the resulting scaffolds were determined from the SEM images. To determine the fiber diameters $40-50$ fibers per sample were measured. The contact angle of fibrous samples was measured by sessile drop method using an automatic drop shape analysis system DSA 10 Mk2 (Kruss, Germany). UHQ-water (produced by Purelab UHQ, Elga, Germany) drops of the volume of $0.2 \mu \mathrm{L}$ were put on each sample and the contact angle was calculated by averaging the results of 10-11 measurements. Crystallinity of pure and modified PLA polymers was determined from DSC curve analysis using DSC 200 F3 Maia differential scanning calorimeter (Netzsch-Gerätebau $\mathrm{GmbH}$ ).

Mechanical properties (tensile strength and Young's modulus) of samples prepared in the form of foil were determined 
TABLE 1: Characterization of fibrous samples.

\begin{tabular}{lcccc}
\hline Type & $\begin{array}{c}\text { Fibre diameter } \\
{[\mu \mathrm{m}]}\end{array}$ & $\begin{array}{c}\text { Contact angle } \\
\text { Degree }\end{array}$ & $\begin{array}{c}\text { Porosity } \\
{[\%]}\end{array}$ & $\begin{array}{c}\text { Crystallinity } \\
{[\%]}\end{array}$ \\
\hline PLA & $2,89 \pm 0,23$ & $108,5 \pm 1,4$ & 83 & 45 \\
PLA + CNT & $2,08 \pm 0,13$ & $95,4 \pm 1,9$ & 80 & 51 \\
PLA + GEL & $1,12 \pm 0,06($ PLA) & $84 \pm 2,2$ & 73 & 41 \\
$80 / 20$ & $2,09 \pm 0,22(\mathrm{GEL})$ & & \\
\hline
\end{tabular}

TABLE 2: Mechanical and electrical properties of fibrous samples.

\begin{tabular}{lccc}
\hline Type & $\begin{array}{c}\text { Tensile strength } \\
\mathrm{MPa}\end{array}$ & $\begin{array}{c}\text { Young's modulus } \\
\mathrm{MPa}\end{array}$ & $\begin{array}{c}\text { El. resistivity } \\
\Omega \mathrm{m}\end{array}$ \\
\hline PLA & $1,8 \pm 0,4$ & $178 \pm 14$ & $>10^{15}$ \\
PLA + CNT & $8,8 \pm 0,7$ & $461 \pm 39$ & 6,7 \\
PLA + GEL & $6,2 \pm 0,3$ & $375 \pm 22$ & - \\
\hline
\end{tabular}

in tensile uniaxial mode with the use of universal machine Zwick testing machine model 1435, using the crosshead speed of 2 [ $\mathrm{mm} / \mathrm{min}]$. Samples examined had the dimensions $5 \mathrm{~mm} \times$ $25 \mathrm{~mm}$. Depending on the type of samples the thickness of the foil varied from $30 \mu \mathrm{m}$ to $170 \mu \mathrm{m}$. Young's modulus of the samples was determined as the slope of the straight line stress-strain relationship. Results (tensile strength and Young's modulus) were obtained as the mean and standard deviation of five measurements.

Electrical resistivity of the samples modified with carbon nanotubes in the form of foil was determined using twopoint probe. The films were measured in a DC field at room temperature.

For in vitro experiments $50 \pm 20 \mu \mathrm{m}$ thick fibrous disks of diameter $16 \mathrm{~mm}$ were cut from the obtained nonwoven samples. Before in vitro study the samples were sterilized with the $\mathrm{H}_{2} \mathrm{O}_{2}$ plasma technique (Sterrad 120, ASP, Johnson \& Johnson, USA).

The essential properties of the fibrous samples are listed in Tables 1 and 2.

The representative sample microstructures analysed by SEM are shown in Figure 1. The diameters of nanofibres are different, depending on the processing variables. The scaffold PLA + GEL consists of two types of nanofibres, that is, PLA-based nanofibres and GEL nanofibres differing in their mean diameter. Porosity of the fibrous samples varies from $73 \%$ to $83 \%$. This parameter can be easily changed by selection of electrospinning conditions. As it results from Table 2 gelatine component plays a role of matrix of hybride PLA + GEL membrane. This component integrates the thinner PLA nanofibres, changes total porosity, and enhances mechanical properties of the resulting PLA + GEL membrane as compared to pure PLA. The fibres vary in the degree of crystallinity and wettability. The presence of carbon nanotubes in a polymer matrix increases nanofibres crystallinity and they become more hydrophobic. Young's modulus of pure PLA samples is $173 \mathrm{MPa}$ and it increases for both CNT-modified PLA nanofibres and hybride samples.
2.3. Biological Preparation. In order to assess the influence of materials upon chondrocytes, tests for viability, cytotoxicity, and genotoxicity as well as cells morphology were performed.

2.3.1. Preparation of Chondrocytes. A study was carried out in accordance with local ethics guidelines, and cartilage samples were collected after obtaining written informed consent from the donors.

A piece of resected tracheal cartilage has been obtained from patients after tracheal surgery. The epithelial layer and tissue surrounding the tracheal cartilage were removed. A small piece of tracheal cartilage was minced into $1 \mathrm{~mm}^{3}$ pieces and washed in phosphate-buffered saline (PBS) containing penicillin and streptomycin. Cartilage specimens were enzymatically digested with collagenase type II (Worthington, Lakewood, NY) in Ham's F12 (PAA, Linz, Austria). After digestion the chondrocyte suspension was filtered using sterile $100 \mu \mathrm{m}$ nylon cell strainers (BD, Falcon, Bedford, MA) and centrifuged for $5 \mathrm{~min}$. Cell number and viability were determined by cell counting using hemocytometer and Trypan blue vital dye. Cell pellet was washed with Ham's F12 once and inoculated into flasks with DMEM/Ham's F12 (PAA, Linz, Austria) medium containing 20\% human serum. Cells were then cultured in an incubator at $37^{\circ} \mathrm{C}$ in a $5.5 \% \mathrm{CO}_{2}$ environment. Medium was exchanged every 48 hours. Cells were passaged when confluence improved by $80 \%$.

2.3.2. Genotoxicity Assay. Genotoxicity was assessed using the single cell gel electrophoresis (SCGE)/comet assay. The method of choice for the genotoxicity testing was a single cell gel electrophoresis (SCGE)/comet assay, a simple and effective way for evaluating DNA damage in single cells. The principle of the assay is based upon the ability of denatured, cleaved DNA fragments to migrate out the nucleus under the influence of an electric field, whereas undamaged DNA migrates slower and remains within the nucleus. Evaluation of the DNA "comet" tail shape and migration pattern allows for assessment of DNA damage. The alkaline comet assay, where electrophoresis takes place in an alkaline buffer, is very sensitive and is used to detect even small amounts of damage, including single- and double-stranded breaks.

The test was performed using dedicated CometAssay Reagent Kit (TREVIGEN, USA), which includes microscopic slides (CometSlides) with surfaces covered with agarose (two wells per slide). The cells were cultured in the appropriate media on the material and on standard TCPS as a control on 24-well plates. The seeding density was 30000 cells per one well and the cultures were conducted for 72 hours 

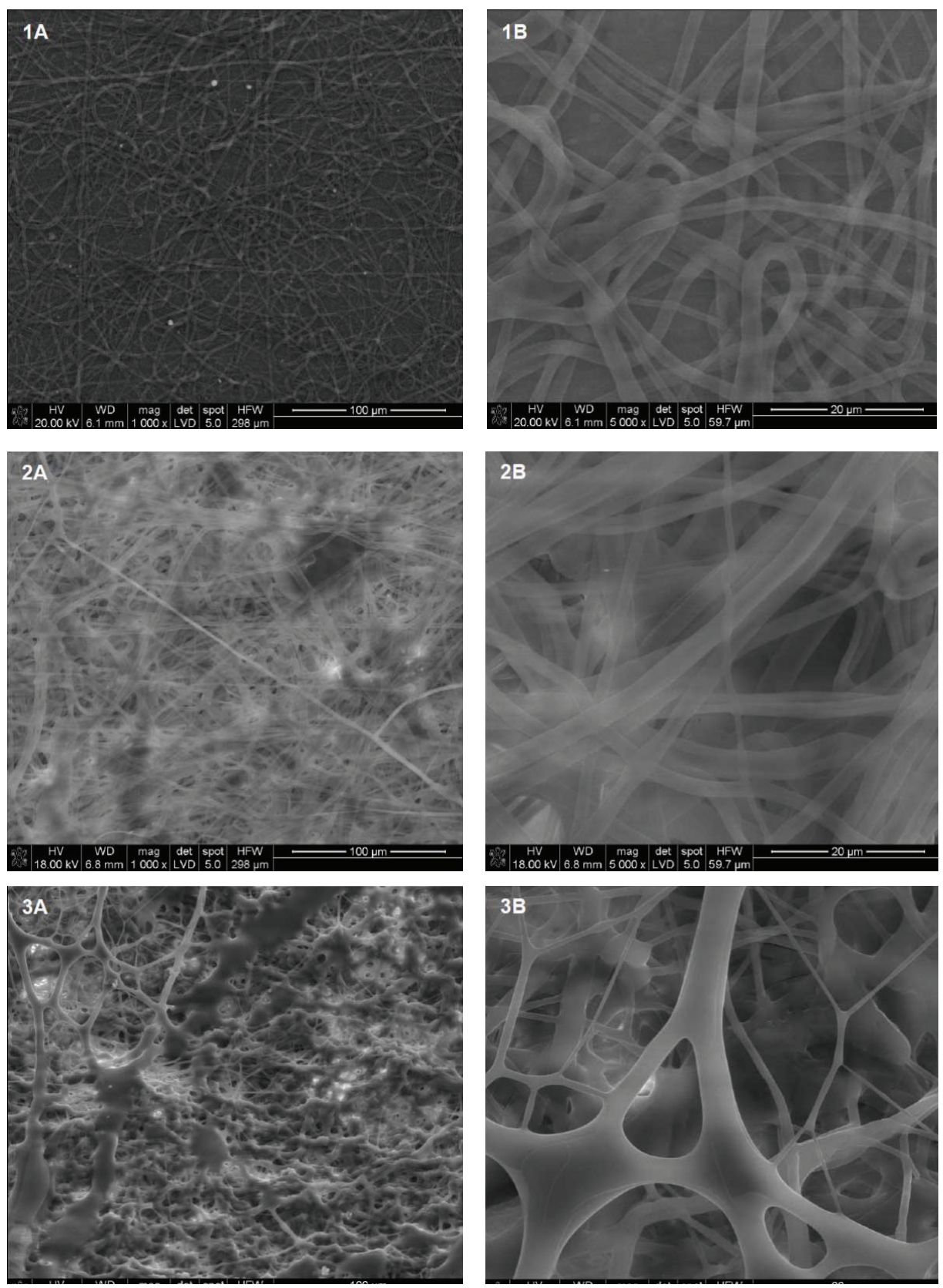

FIgURE 1: SEM images of fibrous scaffolds: (1) PLA, (2) PLA + CNT, and (3) PLA + GEL.

in triplicate under conditions already described. After the time of culture the cells were detached from the culture surface by trypsin digestion and transferred from the culture medium to centrifuge tube. The cells were counted and then pelleted, and the pellet was washed once with ice cold $\mathrm{PBS}(\mathrm{Ca}++$ and $\mathrm{Mg}++$ free) and resuspended at density 105 cells $/ \mathrm{mL}$ in ice cold PBS (Ca++ and $\mathrm{Mg}++$ free). The samples were prepared immediately before running the assay and each experiment was performed in triplicate, including control cells. Prior to the comet assay a viability assay with Trypan blue was conducted and only samples with viability above $75 \%$ were further analyzed in order to exclude false positive results. The study was performed according to the protocol provided by the manufacturer of the Kit. The horizontal electrophoresis was performed with the use of medium FISHER's electrophoresis tank, with $21 \mathrm{~cm}$ distance between electrodes in freshly prepared prechilled alkaline electrophoresis solution, for 30 minutes at $21 \mathrm{~V}$ and $300 \mathrm{~mA}$ in a dark cold room at $4^{\circ} \mathrm{C}$. Finally the slides were stained with diluted SYBR Green I. Stained slides were viewed by epifluorescence microscope AxioImager Z2 (Zeiss, Germany) equipped with a $494 \mathrm{~nm} / 521 \mathrm{~nm}$ filter, CoolCube camera, computer, and a comet assay dedicated software CometScan, Metafer v.3.8.6 (MetaSystems, Germany). Common descriptors of DNA damage for alkaline comet assays are percentage of DNA in the tail and tail moment, combining the amount 
of DNA in tail with distance of migration. In this particular case tail moment olive (TMO) was used, which combines the previously mentioned two characteristics with the total nucleus diameter. One hundred cells per well were scored, totally 300 for each material and corresponding control.

2.3.3. Cytotoxicity Assay. The cytotoxicity of materials was determined using Alamar Blue (Invitrogen).

Alamar Blue is an indicator dye which incorporates an oxidation-reduction (REDOX) indicator that both fluoresces and changes colour in response to the chemical reduction of growth medium, which resulted from cell growth. Prior to cytotoxicity test the cells were cultured in DMEM/F12 (Dulbecco's Modified Eagle Medium/Nutrient Mixture F12, PAN Biotech), which is a 1:1 mixture of DMEM and Ham's F-12. DMEM/F12 was supplemented with 10\% fetal bovine serum (PAA Laboratories), 1\% L-glutamine (PAA Laboratories, Austria), $50 \mu \mathrm{g} / \mathrm{mL}$ gentamycin sulphate (PAN Biotech), $2 \mu \mathrm{g} / \mathrm{mL}$ amphotericin $\mathrm{B}$, and $50 \mu \mathrm{g} / \mathrm{mL}$ ascorbic acid (Sigma).

Human chondrocytes were seeded into 24-well tissue culture plates for a seeding density $40 \times 10^{3}$ cells/well with 3 repetitions for control and tested materials. After 44 hours of incubation at $37^{\circ} \mathrm{C}\left(5 \% \mathrm{CO}_{2}\right)$ medium was removed and fresh medium with $10 \%$ of Alamar Blue (Invitrogen) was added to the cells. Cells were maintained for additional 4 hours. Measurements of the metabolized Alamar Blue were conducted using a Multilabel Plate Reader Victor $\times 5$ (Perkin Elmer) at excitation wave length $560 \mathrm{~nm}$ and the emission wavelength $590 \mathrm{~nm}$. The standard curves for cell numbers were prepared according to the manufacturer's recommendation.

The cell's count was estimated from the reference cell number curve and expressed as the percentage ratio of cell number to the cell number in control cultures.

2.3.4. Fluorescence Microscopy. Morphology of chondrocytes covering the membranes was assessed using inverted microscope Axiovert 40CFL with fluorescence add-on. The cells were dyed by immersion for 30 seconds in $100 \mu \mathrm{L}$ of acridine orange followed by rinsing with PBS. This dye marks both living and dead cells with green fluorescence and red fluorescence, respectively. This happens due to degeneration of cell membrane in the cell fixation process, which enables accumulation of the dye inside the cells. In the case of living cells the nondamaged membrane limits the amount of absorbed orange, which after bonding with RNA molecules emits green fluorescence.

2.4. Statistics. The results were statistically analyzed using the Statistica 8.00. Arithmetic mean and standard deviation $( \pm$ SD) level of significance $(P)$ were counted. Significant differences in mean values were determined by $t$-test for independent samples. It was assumed that the correlation coefficients are significant at $P<0.05$.

\section{Results and Discussion}

Results of the viability test are shown in Figure 2. The study demonstrates high level of cell viability for pure polymer

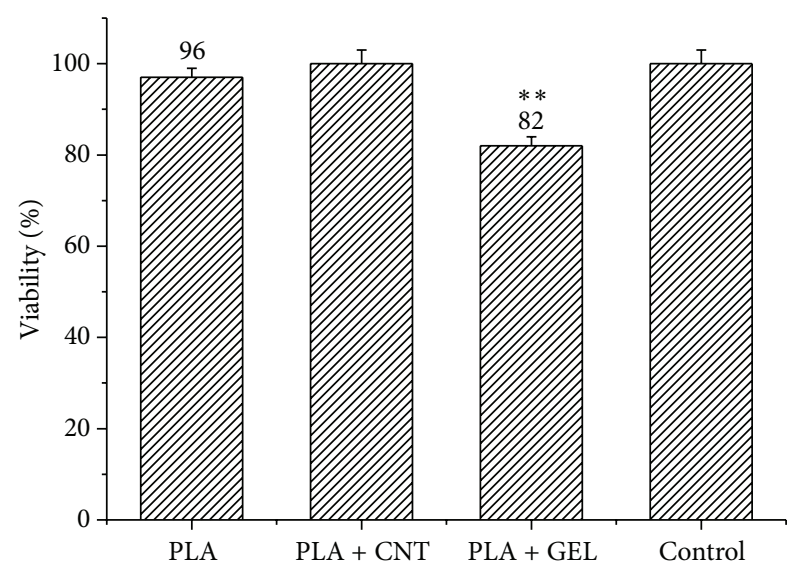

FIGURE 2: Chondrocytes viability seeded on different fibrous supports. ${ }^{* *}$ Statistical difference $P<0.01$ when compared to control.

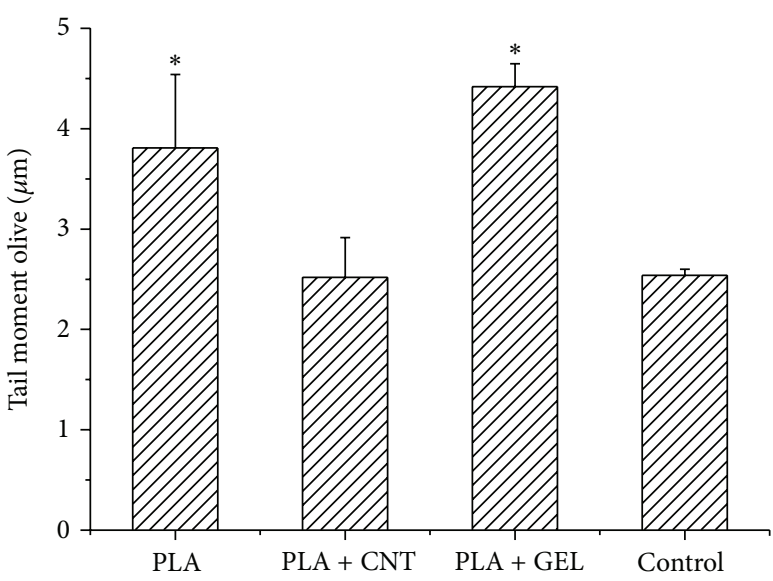

Figure 3: Tail moment olive of PLA-based samples. ${ }^{*}$ Statistical difference, $P<0.05$ when compared to control.

fibrous structure and its modified form, that is, after modification with CNTs and gelatine.

The results of genotoxicity are presented in Figure 3 as the dependence of the tail moment olive to the material type and corresponding controls.

As it results from the diagram the materials studied are not genotoxic for tested chondrocytes and can probably be safely used in humans.

The results show, however, statistical difference between cells cultured on PLA and PLA + GEL materials in comparison to control. The lowest value of TMO was noted for the substrate made of CNTs containing nanofibres. CNTs were used with the purpose to modify physical properties of polymer nanofibres (electrical and mechanical properties). However, biological tests were performed in relatively short time $(72 \mathrm{~h})$, and the polymer nanofibres did not degrade enough to denude carbon nanotubes during degradation process of polymer scaffold.

The results of cytotoxicity test are presented in Figure 4.

All analyzed materials are not cytotoxic for a short period of time ( 48 hours) in chondrocytes cultures. The pure 


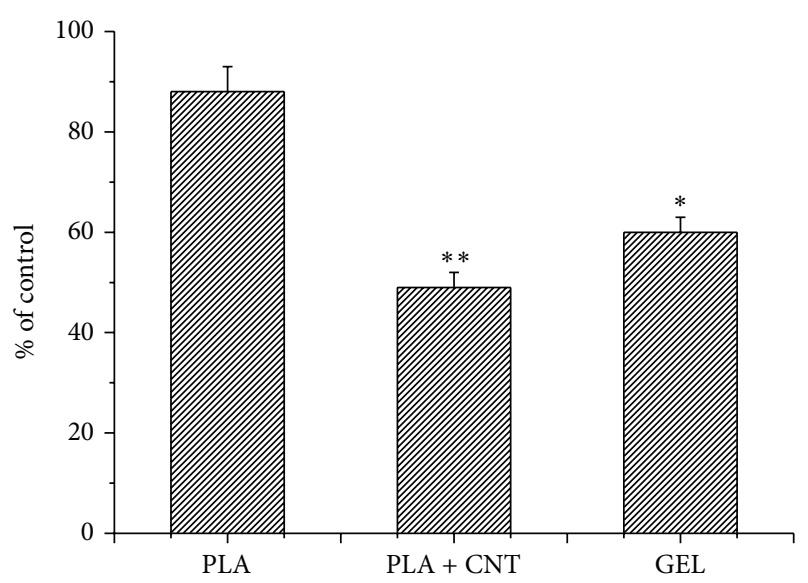

Figure 4: Cytotoxicity test of fibrous scaffolds. ${ }^{*}$ Statistical difference, $P<0.05$ and ${ }^{* *} P<0.01$ when compared to control.

polymer nanofibres perform the highest percentage ratio of cell number to the cell number in control cultures.

Fluorescence microphotograph showing adhesion and morphology of cells on PGA membranes is presented in Figure 5.

In cultures chondrocytes adhered and spread onto polymer matrices. These findings indicate that expanding chondrocytes on fibrous layers are not affected by the scaffold after 72-hour culture.

An ideal cartilage scaffold should mimic native cartilage associated with its mechanical and physiological functions. Several methods of cartilage treatments have been developed with the use of biological materials including osteochondral allografts, autologous chondrocytes, and different polymers [39-41]. In our experiments we manufactured resorbable PLA-based membranes containing carbon nanotubes or gelatine. Nanoscale size fibrous membranes containing nanotubes display very high specific surface area and specific pore structure. An optimal porosity and suitable pore size of cartilage scaffold play an important role in diffusion of degraded products from the polymer structure as well as in migration of cells through the scaffold. Pores should be large enough to allow migration of cells through the scaffold. The microstructure of nanofibrous scaffolds obtained in this work was characterized by high amount of interconnected open pores up to $83 \%$ (Table 1), and the pore sizes were in micron scale (the diameter of random pores was $27+/-13 \mu \mathrm{m}$ ) and were expected to be large enough to allow cell adhesion and migration within the scaffold space and to maintain the proper cartilage morphology. Moreover, by changing the processing variables during electrospinning it is possible to change diameter of nanofibers, pores size, and total porosity of a nanofibrous scaffold $[42,43]$.

The aim of the modification of polymer nanofibrous structure with CNTs in our experiments was to develop a substrate containing an active component for chondrogenesis. Numerous findings support the hypothesis that fibrous carbon components can act as chondrogenic materials [4450]. The carbonaceous materials, including carbon fibres and carbon nanotubes, were successfully applied in the treatment of defects of cartilage. In our experiments the CNTs were added to provide suitable biological and physical properties of nanofibers. The PLA nanofibres are degrading in a biological environment with the time, and it may be expected to expose the surface of carbon nanotubes. The biological tests indicated that the samples containing carbon nanotubes were not toxic [51]. On the other hand, the presence of CNTs in PLA nanofibres modifies their mechanical and electrical properties. Cartilaginous load bearing tissues including airway cartilage are materials with widely differing mechanical properties. Approximately 70 to $85 \%$ of the weight of the whole cartilage tissue is water. The remainder of the tissue is composed of proteoglycans and collagen. Typical values of the modulus of cartilage, depending on the tissue function, vary from $0.5 \mathrm{MPa}$ to $200 \mathrm{MPa}[52,53]$. As it follows from Table 1, PLA + CNT samples have 2.6-fold higher Young's modulus in comparison to pure PLA. The samples represent similar range of elastic properties to natural tissue, and their mechanical strength seems to be high enough to use such fibrous materials for manufacturing scaffold structures. By adding $1 \%$ wt nanotubes significant change in electrical properties was found, that is, from dielectric properties of pure PLA to semiconducting material PLA + CNT $(6.7 \Omega \cdot \mathrm{m})$. The aim to use gelatine with PLA nanofibres was to modify resorption time of the resulting hybride scaffolds [26]. As it follows from our experiments this component also modifies the microstructure of fibrous scaffolds (porosity) and their mechanical properties. We examined the tensile modulus of samples in the form of foil. Gelatine creates cross-linking bonds between PLA nanofibres scaffolds resulting in the 2fold increase of the PLA + GEL modulus as compared to PLA sample.

The preliminary in vitro study indicates that all the PLAbased scaffolds are neither genotoxic nor cytotoxic. In all PLA substrates, modified with both carbon nanotubes and gelatin, human chondrocytes cultured for three days were mostly round in shape without features for dedifferentiation. For repairing defective cartilage tissues engineering utilizes isolated autologous chondrocytes. The cells are seeded on a scaffold surface to achieve cartilage tissue suitable to fill the defect site [54]. One of unsolved problems of such method is chondrocytes dedifferentiation and their transformation into a more fibroblast-like morphology and altered phenotype. Such chondrocyte cultures do not express the true chondrocyte phenotype and often develop into fibrocartilaginous tissue. The surface properties of supporting material structure are an important factor which contributes to cellular interaction with a synthetic material. Generally, hydrophilicity of a surface scaffold is favorable for regeneration of osteochondral tissue [55]. The incorporation of superhydrofilic CNTs to the polymer matrix allows modifying its surface characteristic [28]. In our experiments due to modification of pure PLA fibres with small amount of CNT or gelatine the fibrous samples became more hydrophilic.

\section{Conclusions}

The PLA-based nanofibrous structures in the forms of thin membranes were investigated as scaffolds for cell culture using human chondrocytes. The results indicate that all 

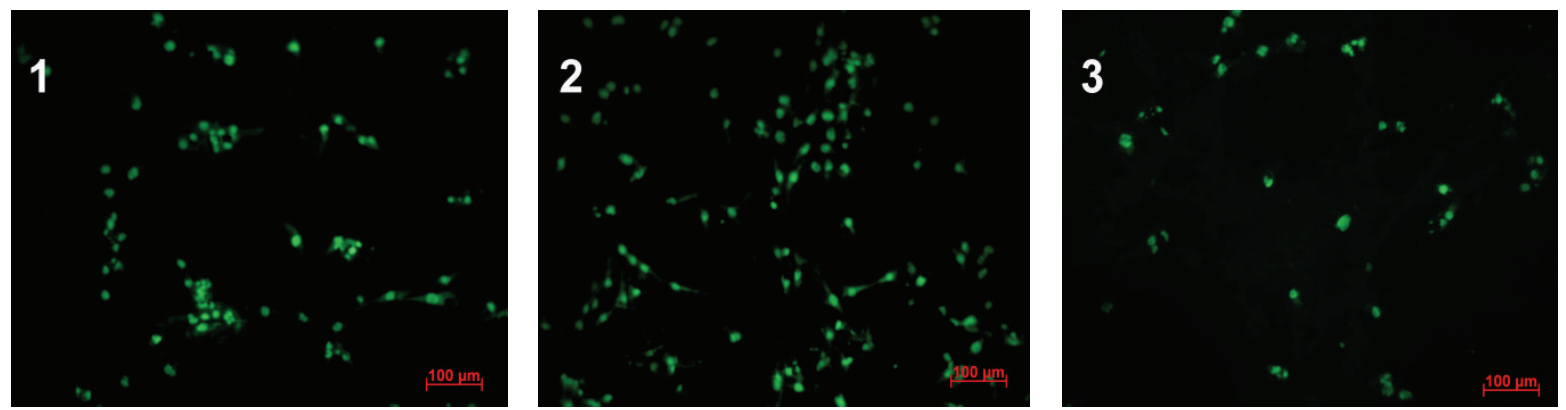

Figure 5: Representative images of chondrocyte cell morphology on (1) PLA, (2) PLA + CNT, and (3) PLA + GEL membrane surface after 72 hours of culture (mag. 10x).

samples differing in their microstructure perform good biocompatibility in contact with human chondrocytes and provide structures which seem to be promising as scaffolds to regenerate defective cartilage. All tested samples were neither genotoxic nor cytotoxic. The biological tests did not reveal significant differences in cells behaviour in contact with materials after three-day cell culture.

The positive preliminary biological assessment of polymer fibrous materials, using electrospinning method, justifies considering them in future design and manufacture of scaffolds for cartilage.

\section{Conflict of Interests}

The authors declare that there is no conflict of interests regarding the publication of this paper.

\section{Acknowledgment}

The authors would like to acknowledge the financial support by the Polish National Science Center, Project no. 2013/11/N/ST8/01169.

\section{References}

[1] I. L. Kim, S. Khetan, B. M. Baker, C. S. Chen, and J. A. Burdick, "Fibrous hyaluronic acid hydrogels that direct MSC chondrogenesis through mechanical and adhesive cues," Biomaterials, vol. 34, no. 22, pp. 5571-5580, 2013.

[2] T. A. E. Ahmed and M. T. Hincke, "Strategies for articular cartilage lesion repair and functional restoration," Tissue Engineering Part B, vol. 16, no. 3, pp. 305-329, 2010.

[3] M. Keeney, J. H. Lai, and F. Yang, "Recent progress in cartilage tissue engineering," Current Opinion in Biotechnology, vol. 22, no. 5, pp. 734-740, 2011.

[4] H. Yokomise, K. Inui, H. Wada, M. Ueda, S. Hitomi, and H. Itoh, "Split transplantation of the trachea: a new operative procedure for extended tracheal resection," The Journal of Thoracic and Cardiovascular Surgery, vol. 112, no. 2, pp. 314-318, 1996.

[5] N. Okumura, T. Nakamura, Y. Takimoto et al., "The repair of tracheal defects using bioabsorbable mesh," ASAIO Journal, vol. 38, no. 3, pp. M555-M559, 1992.
[6] L. Gao, R. McBeath, and C. S. Chen, "Stem cell shape regulates a chondrogenic versus myogenic fate through Racl and Ncadherin," Stem Cells, vol. 28, no. 3, pp. 564-572, 2010.

[7] A. Woods and F. Beier, "RhoA/ROCK signaling regulates chondrogenesis in a context-dependent manner," The Journal of Biological Chemistry, vol. 281, no. 19, pp. 13134-13140, 2006.

[8] B. M. Baker, A. M. Handorf, L. C. Ionescu, W.-J. Li, and R. L. Mauck, "New directions in nanofibrous scaffolds for soft tissue engineering and regeneration," Expert Review of Medical Devices, vol. 6, no. 5, pp. 515-532, 2009.

[9] M. L. A. da Silva, A. Martins, A. R. Costa-Pinto et al., "Cartilage tissue engineering using electrospun PCL nanofiber meshes and MSCs," Biomacromolecules, vol. 11, no. 12, pp. 3228-3236, 2010.

[10] W.-J. Li, R. Tuli, C. Okafor et al., "A three-dimensional nanofibrous scaffold for cartilage tissue engineering using human mesenchymal stem cells," Biomaterials, vol. 26, no. 6, pp. 599609, 2005.

[11] C. Spadaccio, A. Rainer, M. Trombetta et al., "Poly-l-lactic acid/hydroxyapatite electrospun nanocomposites induce chondrogenic differentiation of human MSC," Annals of Biomedical Engineering, vol. 37, no. 7, pp. 1376-1389, 2009.

[12] X. Xin, M. Hussain, and J. J. Mao, "Continuing differentiation of human mesenchymal stem cells and induced chondrogenic and osteogenic lineages in electrospun PLGA nanofiber scaffold," Biomaterials, vol. 28, no. 2, pp. 316-325, 2007.

[13] A. Shafiee, M. Soleimani, G. A. Chamheidari et al., "Electrospun nanofiber-based regeneration of cartilage enhanced by mesenchymal stem cells," Journal of Biomedical Materials Research Part A, vol. 99, no. 3, pp. 467-478, 2011.

[14] S. D. McCullen, H. Autefage, A. Callanan, E. Gentleman, and M. M. Stevens, "Anisotropic fibrous scaffolds for articular cartilage regeneration," Tissue Engineering. Part A, vol. 18, no. 19-20, pp. 2073-2083, 2012.

[15] S. Jia, L. Liu, W. Pan et al., "Oriented cartilage extracellular matrix-derived scaffold for cartilage tissue engineering," Journal of Bioscience and Bioengineering, vol. 113, no. 5, pp. 647-653, 2012.

[16] J. Z. Wu and W. Herzog, "Elastic anisotropy of articular cartilage is associated with the microstructures of collagen fibers and chondrocytes," Journal of Biomechanics, vol. 35, no. 7, pp. 931942, 2002.

[17] W. J. Li, R. Tuli, C. Okafor et al., "A three-dimensional nanofibrous scaffold for cartilage tissue engineering using human mesenchymal stem cells," Biomaterials, vol. 26, no. 6, pp. 599609, 2005. 
[18] E. J. Levorson, P. R. Sreerekha, K. P. Chennazhi, F. K. Kasper, S. V. Nair, and A. G. Mikos, "Fabrication and characterization of multiscale electrospun scaffolds for cartilage regeneration," Biomedical Materials, vol. 8, no. 1, Article ID 014103, 2013.

[19] H. J. Shin, C. H. Lee, I. H. Cho et al., "Electrospun PLGA nanofiber scaffolds for articular cartilage reconstruction: mechan-ical stability, degradation and cellular responses under mechanical stimulation in vitro," Journal of Biomaterials Science, Polymer Edition, vol. 17, no. 1, pp. 103-119, 2006.

[20] Y.-S. Lee and T. L. Arinzeh, "Electrospun nanofibrous materials for neural tissue engineering," Polymers, vol. 3, no. 1, pp. 413426, 2011.

[21] M. P. Prabhakaran, J. Venugopal, C. K. Chan, and S. Ramakrishna, "Surface modified electrospun nanofibrous scaffolds for nerve tissue engineering," Nanotechnology, vol. 19, no. 45, Article ID 455102, 2008.

[22] L. Ghasemi-Mobarakeh, M. P. Prabhakaran, M. Morshed, M.-H. Nasr-Esfahani, and S. Ramakrishna, "Electrospun poly $(\varepsilon-$ caprolactone)/gelatin nanofibrous scaffolds for nerve tissue engineering," Biomaterials, vol. 29, no. 34, pp. 4532-4539, 2008.

[23] J. Y. Lee, C. A. Bashur, A. S. Goldstein, and C. E. Schmidt, "Polypyrrole-coated electrospun PLGA nanofibers for neural tissue applications," Biomaterials, vol. 30, no. 26, pp. 4325-4335, 2009.

[24] F. Yang, R. Murugan, S. Wang, and S. Ramakrishna, "Electrospinning of nano/micro scale poly(L-lactic acid) aligned fibers and their potential in neural tissue engineering," Biomaterials, vol. 26, no. 15, pp. 2603-2610, 2005.

[25] E. Kijeńska, M. P. Prabhakaran, W. Swieszkowski, K. J. Kurzydlowski, and S. Ramakrishna, "Electrospun bio-composite P(LLA$\mathrm{CL}$ )/collagen I/collagen III scaffolds for nerve tissue engineering," Journal of Biomedical Materials Research-Part B Applied Biomaterials, vol. 100, no. 4, pp. 1093-1102, 2012.

[26] S.-Y. Gu, Z.-M. Wang, J. Ren, and C.-Y.Zhang, "Electrospinning of gelatin and gelatin/poly(L-lactide) blend and its characteristics for wound dressing," Materials Science and Engineering $C$, vol. 29, no. 6, pp. 1822-1828, 2009.

[27] M. A. Shokrgozar, F. Mottaghitalab, V. Mottaghitalab, and M. Farokhi, "Fabrication of porous chitosan/poly(vinyl alcohol) reinforced single-walled carbon nanotube nanocomposites for neural tissue engineering," Journal of Biomedical Nanotechnology, vol. 7, no. 2, pp. 276-284, 2011.

[28] B. S. Harrison and A. Atala, "Carbon nanotube applications for tissue engineering," Biomaterials, vol. 28, no. 2, pp. 344-353, 2007.

[29] A. Fraczek-Szczypta, E. Menaszek, and S. Blazewicz, "Some observations on carbon nanotubes susceptibility to cell phagocytosis," Journal of Nanomaterials, vol. 2011, Article ID 473516, 8 pages, 2011.

[30] A. Fraczek-Szczypta, E. Menaszek, T. B. Syeda et al., "Effect of MWCNT surface and chemical modification on in vitro cellular response," Journal of Nanoparticle Research, vol. 14, no. 10, article 1181, 2012.

[31] D. Wu, L. Wu, M. Zhang, and Y. Zhao, "Viscoelasticity and thermal stability of polylactide composites with various functionalized carbon nanotubes," Polymer Degradation and Stability, vol. 93, no. 8, pp. 1577-1584, 2008.

[32] T. J. Webster, M. C. Waid, J. L. McKenzie, R. L. Price, and J. U. Ejiofor, "Nano-biotechnology: carbon nanofibres as improved neural and orthopaedic implants," Nanotechnology, vol. 15, no. 1, pp. 48-54, 2004.
[33] D. Wu, L. Wu, W. Zhou, M. Zhang, and T. Yang, “Crystallization and biodegradation of polylactide/carbon nanotube composites," Polymer Engineering \& Science, vol. 50, no. 9, pp. 1721-1733, 2010.

[34] J. Boczkowski and S. Lanone, "Respiratory toxicities of nanomaterials-a focus on carbon nanotubes," Advanced Drug Delivery Reviews, vol. 64, no. 15, pp. 1694-1699, 2012.

[35] A. A. Shvedova, A. Pietroiusti, B. Fadeel, and V. E. Kagan, "Mechanisms of carbon nanotube-induced toxicity: focus on oxidative stress," Toxicology and Applied Pharmacology, vol. 261, no. 2, pp. 121-133, 2012.

[36] A. J. Andersen, P. P. Wibroe, and S. M. Moghimi, "Perspectives on carbon nanotube-mediated adverse immune effects," Advanced Drug Delivery Reviews, vol. 64, no. 15, pp. 1700-1705, 2012.

[37] C. L. Ursini, D. Cavallo, A. M. Fresegna et al., "Comparative cyto-genotoxicity assessment of functionalized and pristine multiwalled carbon nanotubes on human lung epithelial cells," Toxicology in Vitro, vol. 26, no. 6, pp. 831-840, 2012.

[38] A. Socha and M. Blazewicz, "Microscopic studies of polylactide electrospun fibres designed for tissue engineering scaffolds," Engineering of Biomaterials, vol. 115, pp. 12-17, 2012.

[39] L. E. Freed, D. A. Grande, Z. Lingbin, J. Emmanual, J. C. Marquis, and R. Langer, "Joint resurfacing using allograft chondrocytes and synthetic biodegradable polymer scaffolds," Journal of Biomedical Materials Research, vol. 28, no. 8, pp. 891899, 1994.

[40] J. K. Wise, A. L. Yarin, C. M. Megaridis, and M. Cho, "Chondrogenic differentiation of human mesenchymal stem cells on oriented nanofibrous scaffolds: engineering the superficial zone of articular cartilage," Tissue Engineering_Part A, vol. 15, no. 4, pp. 913-921, 2009.

[41] M. J. Stoddart, S. Grad, D. Eglin, and M. Alini, "Cells and biomaterials in cartilage tissue engineering," Regenerative Medicine, vol. 4, no. 1, pp. 81-98, 2009.

[42] R. Seyedmahmoud, A. Rainer, P. Mozetic et al., "A primer of statistical methods for correlating parameters and properties of electrospun poly(L-lactide) scaffolds for tissue engineering. I. Design of experiments," Journal of Biomedical Materials Research. Part A, vol. 103, no. 1, pp. 91-102, 2015.

[43] R. Seyedmahmoud, P. Mozetic, A. Rainer et al., "A primer of statistical methods for correlating parameters and properties of electrospun poly-l-lactide scaffolds for tissue engineeringPART 2: regression," Journal of Biomedical Materials Research Part A, vol. 103, pp. 103-114, 2014.

[44] R. J. Minns and D. S. Muckle, "Mechanical and histological response of carbon fibre pads implanted in the rabbit patella," Biomaterials, vol. 10, no. 4, pp. 273-276, 1989.

[45] R. J. Minns, D. S. Muckle, and J. E. Donkin, "The repair of osteochondral defects in osteoarthritic rabbit knees by the use of carbon fibre," Biomaterials, vol. 3, no. 2, pp. 81-86, 1982.

[46] P. Pongor, J. Betts, D. S. Muckle, and G. Bentley, "Woven carbon surface replacement in the knee: independent clinical review," Biomaterials, vol. 13, no. 15, pp. 1070-1076, 1992.

[47] M. Brittberg, E. Faxen, and L. Peterson, "Carbon fiber scaffolds in the treatment of early knee osteoarthritis: a prospective 4year followup of 37 patients," Clinical Orthopaedics and Related Research, no. 307, pp. 155-164, 1994.

[48] K. Meister, A. Cobb, and G. Bentley, "Treatment of painful articular cartilage defects of the patella by carbon-fibre implants," Journal of Bone and Joint Surgery: Series B, vol. 80, no. 6, pp. 965-970, 1998. 
[49] A. Abarrategi, M. C. Gutiérrez, C. Moreno-Vicente et al., "Multiwall carbon nanotube scaffolds for tissue engineering purposes," Biomaterials, vol. 29, no. 1, pp. 94-102, 2008.

[50] M. A. Correa-Duarte, N. Wagner, J. Rojas-Chapana, C. Morsczeck, M. Thie, and M. Giersig, "Fabrication and biocompatibility of carbon nanotube-based 3D networks as scaffolds for cell seeding and growth," Nano Letters, vol. 4, no. 11, pp. 2233-2236, 2004.

[51] A. Wiecheć, E. Stodolak-Zych, A. Frą̧czek-Szczypta, M. Błazewicz, and W. M. Kwiatek, "The study of human osteoblast-like MG 63 cells proliferation on resorbable polymer-based nanocomposites modified with ceramic and carbon nanoparticles," Acta Physica Polonica, vol. 121, no. 2, pp. 546-550, 2012.

[52] G. R. Higginson and J. E. Snaith, "The mechanical stiffness of articular cartilage in confined oscillating compression," Engineering in Medicine, vol. 8, no. 1, pp. 11-14, 1979.

[53] J. K. Rains, J. L. Bert, C. R. Roberts, and P. D. Pare, "Mechanical properties of human tracheal cartilage," Journal of Applied Physiology, vol. 72, no. 1, pp. 219-225, 1992.

[54] K. R. Brodkin, A. J. García, and M. E. Levenston, "Chondrocyte phenotypes on different extracellular matrix monolayers," Biomaterials, vol. 25, no. 28, pp. 5929-5938, 2004.

[55] H. Wu, Y. Wan, X. Cao, and Q. Wu, "Proliferation of chondrocytes on porous poly(DL-lactide)/chitosan scaffolds," Acta Biomaterialia, vol. 4, no. 1, pp. 76-87, 2008. 

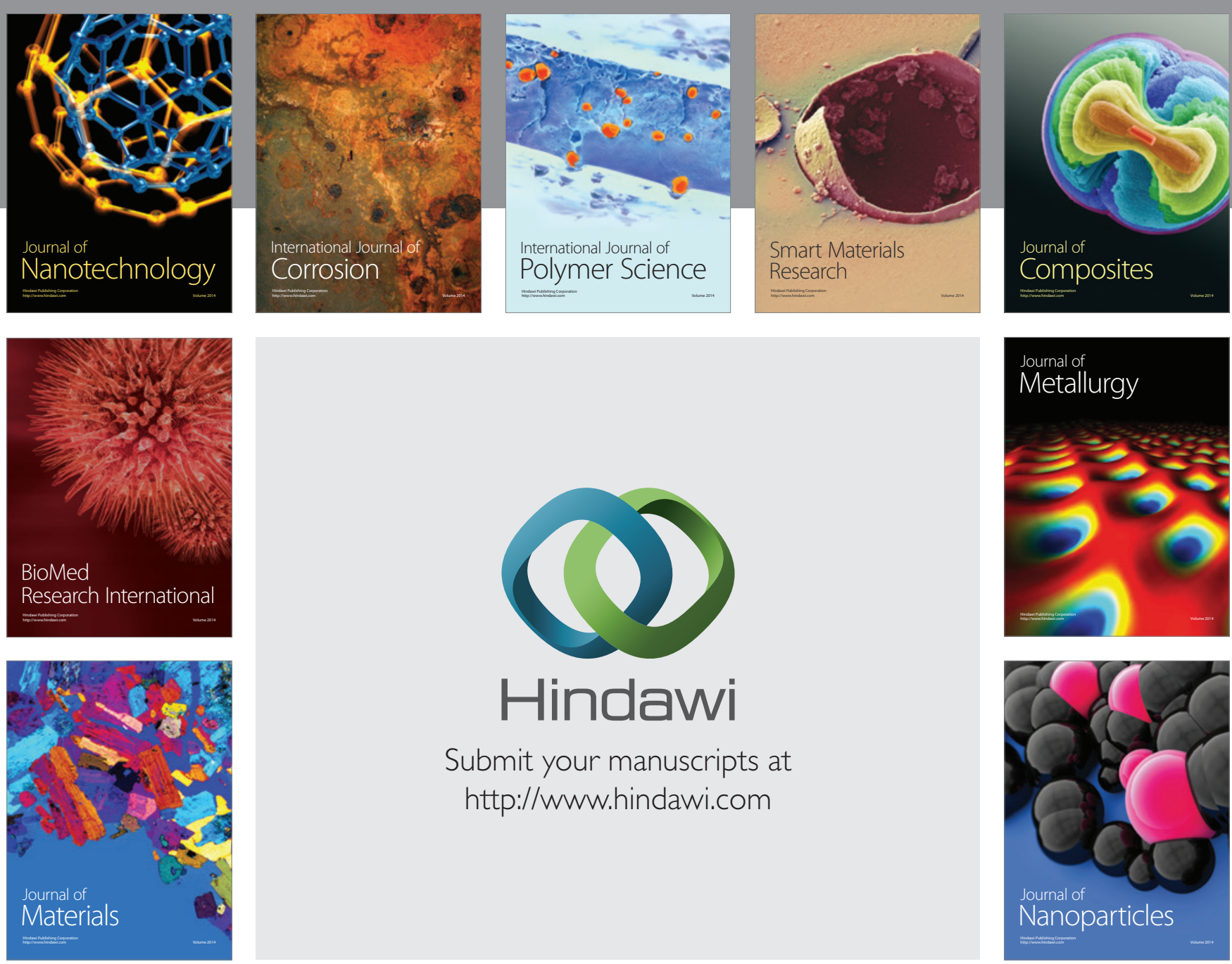

Submit your manuscripts at http://www.hindawi.com
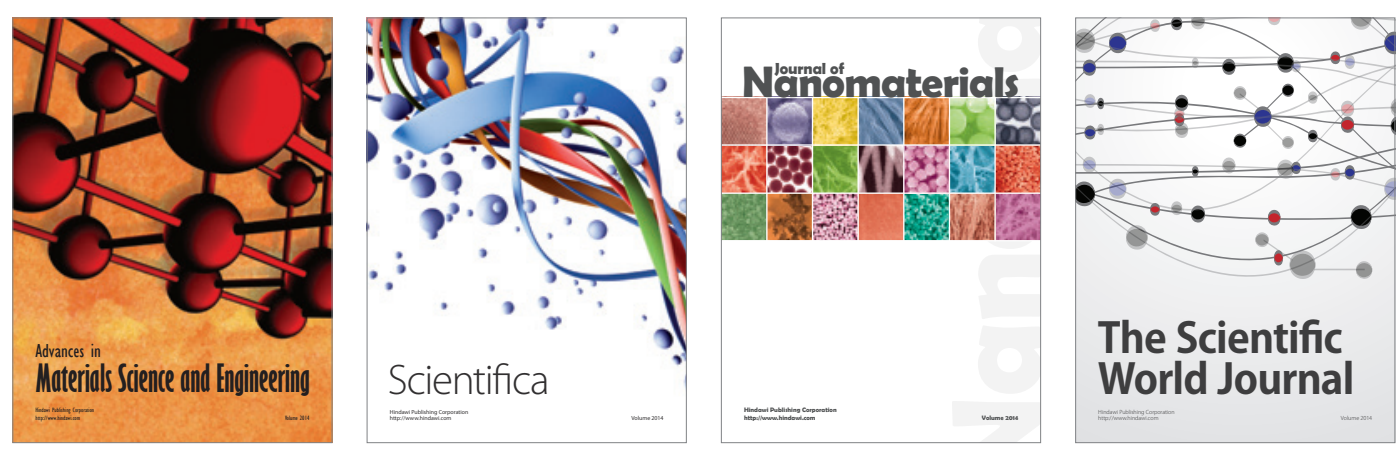

\section{The Scientific World Journal}
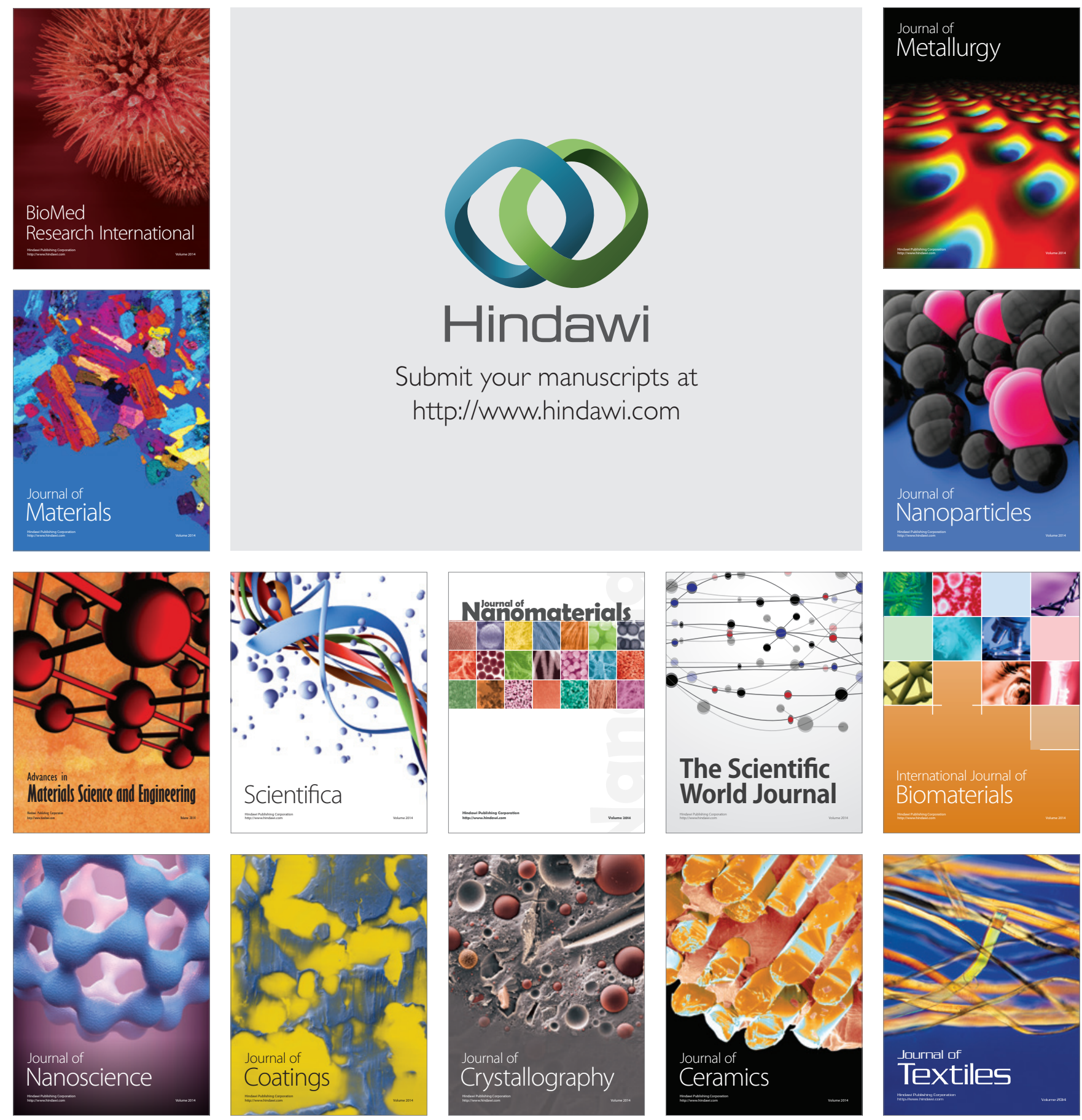